\title{
Attitude, Awareness, and Interest towards Personalized Nutrition among Educated Men and Women in Chennai.
}

\author{
Durga Priyadarshini R ${ }^{1}$, Dr. Mahjabeen ${ }^{2 *}$ \\ ${ }^{1}$ Post Graduate Scholar, Department of PG studies and Research in Home Science, JBAS College for Women, \\ Chennai, India \\ ${ }^{2}$ Assistant Professor, Department of PG studies and Research in Home Science, JBAS College for Women, Chennai, \\ India
}

\begin{abstract}
The present investigation attempts to study the attitude, awareness and interest towards personalized nutrition among educated men and women in Chennai. A random sample of 120 adults was selected for the present investigation. Out of the 120 samples, 60 were males and 60 were females. Further, the 60 males were divided into 20 doctors, 20 lecturers and 20 software professionals. The same distribution was followed for all the 60 educated female professionals. The tool used for the present study was framed by the corresponding author herself. The results drawn from the present study showed that the attitude and awareness towards personalized nutrition was higher among female participants. With respect to occupation, the awareness towards personalized nutrition was higher among doctors, followed by lecturers and software professionals. Results also indicated that lectures and doctors as a profession have an influence on their level of attitude, awareness, and interest towards personalized nutrition. On the other hand, the findings showed significant association between software professionals and their attitude towards personalized nutrition. Further, a positive relationship was found between attitude and interest towards personalized nutrition among adults regardless of profession.
\end{abstract}

Keywords: Personalized Nutrition; Nutritional Genomics; Nutrigenetics; Nutrigenomics; Awareness; Interest; Attitude; India.

Accepted on August 25, 2017

\section{Introduction}

Nutrigenomics refers to both the study of how the food, beverages and supplements we consume affect our genes and how our genes can influence our body's response to what we eat. Nutrigenomics is sometimes referred to as nutrigenetics and includes the study of how genetic variations affect food intake and eating behaviours [1].

Not all individuals respond similarly to food, a concept crystallized by Galen about 1800 years ago: "No cause can be efficient without an aptitude of the body". Over the past, there has been growing recognition of the importance of how genes influence our nutritional status, which directly impacts our health. The human genome consists of about 25,000 genes and virtually all can exist in different forms. The variations in our genomes make us unique from one another. The colour of our eyes and hair are not only determined by genetic variations but also by how we metabolize and utilize the nutrients we ingest.

Subsequent to the mapping of the human genome new possibilities have opened for understanding the genetic background to diseases, not at least for understanding the relation between genes, nutrition and health. One influential idea in this prospect for tailor-made nutritional advice based on genetic test is personalized nutrition [2].

Nutrigenomics is a revolutionary way of viewing the food, just for not substance, but as a pharmaceutical capable of reversing disease and stalling the rigors of aging. As part of the approach, nutrigenomics involves finding markers of the early phase at which intervention with nutrition can return the patient to health [3].

Impressive examples of nutrigenomics are Resveratrol being present in red wine, is a nutrient that stimulates a gene which protects tissues from free radical damage. Another nutrient that affects your genes is folate which is needed by the body to make DNA. When the required amount of folate is not consumed, it leads to higher risk of developing cancer. The fact, that common diet contains many bioactive substances that can through the interaction with receptors, activate or modulate the transcription of target genes or directly cause the rearrangement of chromatin structure, is widely accepted, but not often recognized in the design and interpretation of genetic and epidemiologic studies [4].

Rapid progress in human genome decoding has accelerated the search for the role of gene polymorphisms in the pathogenesis of complex multifactorial diseases. There is an apparent progress in the field with hundreds of new gene polymorphisms discovered and characterized, however firm evidence consistently linking them with the pathogenesis of complex chronic diseases is still limited.

Nutrigenomics seem to have an advantage over and above compared to age, sex, body mass index (BMI), diet, physical activity and health status based nutrition advice. The reason is that genetic differences between individuals, which may interact with phenotype and co-determine health impacts of dietary 
Citation: Durga Priyadarshini R, Mahjabeen. Attitude, awareness, and interest towards personalized nutrition among educated men and women in chennai. J Nutr Hum Health. 2017;1(2):9-12

choices, are explicitly taken into account. Though gene-based dietary advice is quite popular among the Canadians and few other foreign countries, the very concept is totally new to India and not many are aware of their availability which might prove beneficial if made known. Hence, there is a need to analyse/ assess the level of awareness, attitude, and interest of educated men and women on personalized nutrition in India.

\section{Methodology}

\section{Sample}

For the present investigation 120 educated adults were selected. Out of the 120 samples, 60 were males and 60 were females. Further, the 60 males were divided into 20 doctors, 20 lecturers and 20 software professionals. The same distribution was followed for all the 60 educated female professionals.

\section{Tools used}

The tool, a questionnaire was devised by the investigator herself in order to analyse and assess the attitude, awareness and interest of educated men and women on personalized nutrition.

\section{Procedure}

The questionnaire consists of 30 questions under 3 domains with 10 questions in health and nutrition awareness inventory, 10 questions in personalized nutrition attitude scale and 10 questions in personalized nutrition interest inventory. The respondent had to make their choice of response in the questionnaire itself.

\section{Statistical Analysis}

The collected data was tabulated and analysed using the following statistical techniques in IBM SPSS statistics software to obtain the results.

1. Mean

2. Standard Deviation

3. Independent t-test

4. Multivariate Analysis of Variances

5. Pearson's Correlation Coefficient

\section{Results}

\section{Section 1}

This section deals with the comparison of attitude, awareness and interest towards personalized nutrition among educated men and women. Statistical analysis was done and the results are presented in the table below.

A perusal of table 1 indicates that there is a significant difference in attitude $(\mathrm{t}(118)=2.35, \mathrm{p}=.020)$ and awareness $(\mathrm{t}(118)=$ $2.61, \mathrm{p}=.010)$ towards personalized nutrition between educated men and women. This finding shows that the attitude and awareness towards personalized nutrition appears to be higher among educated women.

But no significant difference was found in the level of interest towards personalized nutrition between educated men and women thereby showing that the level of interest towards
Table 1. Difference between educated men and women on their attitude, awareness and interest towards personalized nutrition

\begin{tabular}{|c|c|c|c|c|c|}
\hline Variable & \multicolumn{2}{|c|}{$\mathbf{N}$} & \multicolumn{2}{c|}{ Mean } & t-value \\
\hline & Male & Female & Male & Female & \\
\hline Attitude & 60 & 60 & 18.36 & 19.55 & $2.35^{*}$ \\
\hline Awareness & 60 & 60 & 23.03 & 24.48 & $2.61^{\text {** }}$ \\
\hline Interest & 60 & 60 & 20.01 & 19.9 & 0.25 \\
\hline Note. ${ }^{*} \mathbf{p}<. \mathbf{0 5},{ }^{* *} \mathbf{p}<.01$ & \multicolumn{4}{|l}{} \\
\hline
\end{tabular}

personalized nutrition appears to be the same among educated men and women.

\section{Section 2}

This section deals with the comparison of attitude, awareness and interest towards personalized nutrition among different professions. Multivariate Analysis of Variances (2 way ANOVA) was carried out and the results are presented in the table below.

A perusal of table 2 indicates that there is no significant difference in attitude towards personalized nutrition between lecturers, doctors and software professionals. This finding shows that the level of attitude towards personalized nutrition appears to be the same among lecturers, doctors and software professionals.

Whereas, significant difference was found between lecturers, doctors and software professionals on their level of awareness towards personalized nutrition $(\mathrm{F}(2,1)=15.32 \mathrm{p}=.000)$. This finding shows that the level of awareness towards personalized nutrition appears to be higher among doctors $(\mathrm{m}=25.15)$ followed by lecturers $(\mathrm{m}=24.30)$ and software professionals $(\mathrm{m}=21.82)$.

A perusal of table 2 also shows that there is no significant difference in interest towards personalized nutrition between lecturers, doctors and software professionals. It indicates that the level of interest towards personalized nutrition appears to be the same among lecturers, doctors and software professionals.

\section{Section 3}

This section deals with the association between attitude, awareness, interest towards personalized nutrition and various occupation.Significant association was found between lecturers and their attitude $(\mathrm{x} 2=22.76, \mathrm{p}=.002)$, awareness $(\mathrm{x} 2=$ 23.00, $\mathrm{p}=.002)$ and interest $(\mathrm{x} 2=27.93, \mathrm{p}=.001)$ towards personalized nutrition indicating that lectureship as a profession did have an influence on their level of attitude, awareness and interest towards personalized nutrition. With respect to doctors, Significant association was found between their profession and their attitude $(x 2=30.20, p=.000)$, awareness $(x 2=18.79, p=$ $.009)$ and interest $(\mathrm{x} 2=17.26, \mathrm{p}=.016)$ towards personalized nutrition indicating that lectureship as a profession did have an influence on their level of attitude, awareness and interest towards personalized nutrition.

Results also suggested significant association between software professionals and their attitude towards personalized nutrition $(\mathrm{x} 2=15.540, \mathrm{p}=.049)$ but no significant association was found regarding their awareness and interest towards personalized nutrition. 
Table 2. Difference between lecturers, doctors and software professionals on their attitude, awareness and interest towards personalized nutrition

\begin{tabular}{|c|c|c|c|c|c|c|c|}
\hline \multirow[t]{2}{*}{ Variable } & \multicolumn{3}{|c|}{$\mathbf{N}$} & \multicolumn{3}{|c|}{ Mean } & \multirow[t]{2}{*}{$\mathbf{F}$} \\
\hline & Lecturers & Doctors & Software Professionals & Lecturers & Doctors & Software Professionals & \\
\hline Attitude & 40 & 40 & 40 & 18.3 & 18.95 & 19.62 & 2.27 \\
\hline Awareness & 40 & 40 & 40 & 24.3 & 25.15 & 21.82 & $15.32^{* *}$ \\
\hline Interest & 40 & 40 & 40 & 19.37 & 20.27 & 20.22 & 1.59 \\
\hline
\end{tabular}

\section{Section 4}

This section deals with the relationship between attitude, awareness, and interest towards personalized nutrition.

It was found that there was no relationship between awareness and attitude as well as between awareness and interest but a positive relationship was found between attitude and interest towards personalized nutrition among adults regardless of profession $(\mathrm{r}=.432 \mathrm{p}<0.01)$.

\section{Discussion}

The results drawn from the present study showed that the attitude and awareness towards personalized nutrition was higher among female participants. But no difference was observed in the level of interest towards personalized nutrition among educated men and women. This is supported by [5]. A study by [6] revealed that only $27 \%$ of the respondents have a positive attitude towards the new possibility, and they would be glad to use this new service in order to stay healthy.

With respect to occupation, the awareness towards personalized nutrition was higher among doctors, followed by lecturers and software professionals. But the level of attitude and interest towards personalized nutrition appeared to be the same among educated men and women of different occupation. The above result is substantiated with the Canadian telephonic survey conducted by [7] where the respondents demonstrated limited knowledge and awareness, but nevertheless had favourable perceptions of nutrigenomics.

Results also indicated that lectures and doctors as a profession have an influence on their level of attitude, awareness, and interest towards personalized nutrition. This is supported by [8-11]. The findings of the present study showed significant association between software professionals and their attitude towards personalized nutrition.

Further it was seen that there was no relationship between awareness and attitude as well as between awareness and interest but a positive relationship was found between attitude and interest towards personalized nutrition among adults regardless of profession. The above finding is supported by [12-14].

\section{Conclusion}

The findings of the study are limited to educated adults of only 3 professions living in Chennai city (India). Moreover, the study was conducted on a limited sample of 120 adults. Therefore it seems desirable to conduct similar studies on large samples taking many other variables into consideration.

\section{Acknowledgment}

First and foremost I would like to thank God for everything. Without the support of my family and friends it would have not been possible to complete my research with ease. I would also like to thank my guide and institution for this opportunity.

\section{References}

1. Eny KM, El-Sohemy A. Genetic Detrminants of Ingestive Behaviour: Sensory, Energy Homeostasis and Food Reward Aspects Of Ingestive Behaviour. Elsevier Inc. 2010;149-60.

2. Gorman $U$ Ethical issues raised by personalized nutrition based on genetic information. Genes and nutrition. 2006;1:13-22.

3. Bhatt SN, Sharma AD. Nutirgenomics: a non-conventional therapy. International Journal of Pharmaceutical Sciences Review and Research. 2011;8 (2):100-5.

4. DeBusk R. Diet-related disease, nutritional genomics and food and nutrition professionals. Journal of American Diet Association. 2009;109(3):410-13.

5. Ana PO, Magdalena L, Libertad TF, et al. Awareness of Direct-to-Consumer Genetic Tests and Use of Genetic Tests Among Puerto Rican Adults. Journal of Preventing Chronic Diseases.2009;8(5):110.

6. Szakály Z, Polereczki S, Kovács. Consumer attitudes toward genetic testing and personalised nutrition in Hungary. International Journal of food science. 2016;45(4):6.

7. Castle D, Weir D, Morin K, et al. Public knowledge, awareness and perceptions of Nutrigenomics A study of Canadian perspectives. Agro Food Industry Hi Tech. 2010; 21(1):14-17.

8. Cristiana P, Angeliki K, Aglaia B. Ascertainment and critical assessment of the views of the general public and healthcare professionals on nutrigenomics in Greece. Journal of Nutrigenomics. 2012;9(2):201-10.

9. Bailey LB, Gregory JF. Polymorphisms of Methylene tetra hydro folate reductase and Other Enzymes: Metabolic Significance, Risks and Impact on Folate Requirement. Journal of Nutrition. 1999;129(5) 919-22.

10. Garcia-Balio BC, Toguri KM, El-Sohemy A. Genetic variation in taste and its influence on food selection. A Journal of Integrative Biology.2009;13(1):69-80.

11. Loktionov A. Common gene polymorphisms and nutrition: emerging links with pathogenesis of multifactorial chronic diseases (review). Journal of Nutritional Biochemistry. 2003;14 (8): 426-51.

12. Ries NM, Hyde-Lay R, Caulfield T. Willingness to Pay for Genetic Testing: A Study of Attitudes in a Canadian Population. Journal of Public Health Genomics.2010;13:292-300. 
Citation: Durga Priyadarshini R, Mahjabeen. Attitude, awareness, and interest towards personalized nutrition among educated men and women in chennai. J Nutr Hum Health. 2017;1(2):9-12

13. Nielsen DE, El-Sohemy A. Disclosure of genetic information and change in dietary intake : A randomized controlled trial. Plos one. 2015;9(11): e112665.
14. Nielsen DE, Shih S, El-Sohemy A.Perceptions of genetic testing for personalized nutrition: a randomized trial of DNA-based dietary advice. Journal of Nutrigenetics and Nutrigenomics. 2015;7(2): 94-104.

\section{*Correspondence to:}

Dr. Mahjabeen

JBAS College for Women Chennai India

Tel: 04424364152

E-mail: jabeenhasan@gmail.com 